\title{
UNIVERSITYOF BIRMINGHAM

\section{Consideration of practice education within a regional teaching partnership employing a communities of practice lens}

Haworth, Simon

DOI:

10.1080/09503153.2018.1476478

License:

Other (please specify with Rights Statement)

\section{Document Version}

Peer reviewed version

Citation for published version (Harvard):

Haworth, S 2019, 'Consideration of practice education within a regional teaching partnership employing a communities of practice lens', Practice, vol. 31, no. 3, pp. 163-186.

https://doi.org/10.1080/09503153.2018.1476478

Link to publication on Research at Birmingham portal

Publisher Rights Statement:

This is an Accepted Manuscript of an article published by Taylor \& Francis in Practice on , available online:

'https://doi.org/10.1080/09503153.2018.1476478

\section{General rights}

Unless a licence is specified above, all rights (including copyright and moral rights) in this document are retained by the authors and/or the copyright holders. The express permission of the copyright holder must be obtained for any use of this material other than for purposes permitted by law.

-Users may freely distribute the URL that is used to identify this publication.

- Users may download and/or print one copy of the publication from the University of Birmingham research portal for the purpose of private study or non-commercial research.

- User may use extracts from the document in line with the concept of 'fair dealing' under the Copyright, Designs and Patents Act 1988 (?)

- Users may not further distribute the material nor use it for the purposes of commercial gain.

Where a licence is displayed above, please note the terms and conditions of the licence govern your use of this document.

When citing, please reference the published version.

Take down policy

While the University of Birmingham exercises care and attention in making items available there are rare occasions when an item has been uploaded in error or has been deemed to be commercially or otherwise sensitive.

If you believe that this is the case for this document, please contact UBIRA@lists.bham.ac.uk providing details and we will remove access to the work immediately and investigate. 


\section{A Systematic Review of Research on Social Work Practice with Single}

\section{Fathers}

\section{Simon Haworth}

Correspondence to: Simon Haworth, Department of Social Work \& Social Care, University of Birmingham, Edgbaston, Birmingham B15 2TT.

\section{Email: s.p.c.haworth@bham.ac.uk}

\section{Abstract:}

This paper presents a systematic literature review that explored social work practice with single fathers. The literature search identified 7 studies, both qualitative and quantitative in nature. The small number of studies identified that met the inclusion criteria suggests that single fathers are under-researched in social work, which aligns with their relative invisibility in practice and welfare debates. The findings suggest that social workers did not genuinely or comprehensively understand the needs of single fathers and did not effectively engage with them. This paper's discussion relates these findings to Doucet's interpretations of borderwork and border crossing and relates these concepts to questions of whether social work is inclusive of single fathers or assesses their needs fairly. The discussion is located within wider discourses that propose that societal assumptions about the feminised role of caring and lone parenthood exclude fathers and place responsibility for children primarily on mothers. This paper found that current research into social work with single fathers has not effectively considered the array of social influences on their capacities to parent and thus areas for future research are suggested to promote an agenda of inclusion for single fathers and greater awareness for social work and social work practitioners.

Keywords: single fathers, social work, borderwork, border crossing, systematic literature review. 


\section{Introduction}

This paper explores the topic of social work practice with single fathers through a systematic review of the available research and examines what can be learnt from the published studies in this area. The primary aims of this review were to explore what the research says about the experiences of single fathers in their interactions with social work and to ask whether social work practice is inclusive or excluding of single father families. It utilises the concept of borderwork (Doucet, 2007) to develop understanding of single fathers' experiences of marginalisation and exclusion within this professional context. It locates these arguments within the context of western welfare states that remain predicated on traditional family norms and gendered expectations around care and caring. This paper seeks to encourage research that develops more effective and constructive engagement with single fathers and supports their participation in social work processes and avenues of support.

According to the Office for National Statistics (ONS), of the 2.9 million lone parent families in the UK in 2016, 1.9 million had dependent children, with $10 \%$ of those with dependent children headed by single fathers. This equates to 190,000 families headed by single fathers in the UK (ONS, 2016).

Single fatherhood is not a straightforward term, rather its definition is used in different ways by different individuals, dependent on the context in which it is being used. In fact, as Letablier and Wall (2018) suggest, there is a lack of a common agreed definition for Ione parenthood more generally. Duncan and Edwards (1997) define lone parent families as those 'where a parent lives with his/her dependent children, without a spouse/partner, either on their own or in multi-unit households' (p.3). The official UK government definition of a lone parent, according to ONS (2016), is 'a parent with a dependent child living in a household with no other people (whether related to that dependent child or not)' (p.5).

Building upon these definitions, for the purposes of this paper, single fathers will be understood as: 'Fathers acting as the primary caregivers for their child(ren) through sole or joint care arrangements with no wife or partner living with them'. I recognise that this definition is open to debate and, indeed, improvement.

\section{The wider context}

This review was conducted within the wider contexts of single parenthood in the UK, government policies, societal attitudes and the continuing progression of social work as a profession. A number of scholars have commented that the British welfare state remains 
primarily predicated on traditional family and gendered parenting roles (Christie, 2006; Daly \& Rake, 2003; Ferguson \& Hogan, 2004; Pascall, 2012). The UK welfare state and dominant societal discourses have, and, indeed continue to, placed mothers as children's primary carers and fathers in a supporting role, as the breadwinners for the family (Featherstone, 2009; Christie, 2001; Doucet, 2000). Having stated this, authors such as Brown et al (2009) suggest that societal norms are progressing towards greater appreciation of father engagement. However, general public attitudes persist to identify mothers as more able childcarers (Parker \& Livingston, 2017).

Dominant models of parenting and normative expectations are not static, but are structurally and socially highly influential, influencing the views of policymakers, professionals and parents themselves (Christie, 2006; Philip, 2013). For instance, in their enquiry of 2014, the Equal Opportunities Committee in Scotland publicised that services, including children and families social work, often equate parent to mean mother and have not kept up with the changing expectations of fathers in society (Scottish Parliament, 2014).

There is growing interest in research into social work with fathers and some enlightening articles by a range of scholars including Featherstone (2009, 2012, 2017), Scourfield (2001, 2006), Ashley (2006), Gupta (2015), Ferguson and Hogan (2004) and Brandon, Philip and Clifton (2017). Having stated this, Shapiro and Krysik (2010) found that within social work journals, only $7.26 \%$ of family-related articles considered fathers. Research repeatedly finds that fathers are not regularly engaged with in social work practice and that social workers are not supported or encouraged to work with fathers in meaningful ways; rather, research often finds that practice focusses mostly on mothers, with the burden of care and responsibility and blame for family difficulties, neglect and abuse placed firmly on their shoulders (Ashely et al, 2017; Brandon, Philip and Clifton, 2017; Brewsaugh, Masyn \& Salloum, 2018; Featherstone et al; 2017; Ferguson \& Hogan, 2004; Scourfield 2006).

Problematically, social work research itself has tended to use the terms parents and families as proxies for mothers (Brewsaugh, Masyn \& Salloum, 2018; Risley-Curtiss \& Heffernan, 2003; Strega et al, 2008), mirroring issues in policy and practice and potentially further excluding fathers in the process. Furthermore, single fathers are single parents and the perception that single parents 'always take and don't give back to the state' is so routinely suggested that it can be considered normative (Garner 2009). Based on this thinking, all single parents can be understood to be marginalised to varying degrees through dominant societal narratives. 


\section{The research questions}

In light of the above information, these research questions emerged and were used to construct this literature review:

\section{Primary:}

What can we learn about social work practice with single fathers from the published research studies?

\section{Sub questions:}

I. What are the experiences of single fathers within children and families social work practice?

II. What are the attitudes and narratives of children and families social workers towards single fathers?

III. How do these attitudes and narratives of children and families social workers influence the experiences of single fathers of social work practice?

IV. Is children and families social work practice inclusive and supportive of single fathers, and if so what are the key features of inclusive and supportive practice with single fathers?

\section{Theoretical standpoint}

A theoretical framework assists the definition of relevant research questions and can help provide the scope of a literature review (Paterson et al, 2001). A variety of theoretical frameworks have been used to examine fatherhood, notably feminist theory, sociobiological theory and psychodynamic perspectives (Scourfield, 2001). Most social work research into fathers adopts a feminist framework (e.g. Ashley et al, 2006; Featherstone, 2009; Gupta, 2015). However, a feminist framework can be considered to develop only partial understanding, with its central focus on the omnipotence and domination of men in our society. As a result it is likely that this theory struggles to fully explain the experiences of single fathers, given the likelihood that, in many contexts, they can be considered to hold non-hegemonic masculinities (Smith, 1998), be viewed as failed and deviant men through potentially not working and acting as primary caregivers (Doucet, 2007), and to engage in traversing female-dominated and multifaceted maternal worlds (Scourfield, 2001).

The concept of borderwork was originally envisioned by Thorne (1993), has been briefly discussed in relation to social work by Featherstone (2009), but has been more significantly developed by Doucet. Doucet $(2000,2006,2007)$ has written about men as 
primary caregivers and her work draws attention to the socially constructed gendered norms of parenting and masculinity. She describes borderwork as 'spaces and times where intense gender differences are intensely perceived and experienced' (2007, p.42). Meanwhile, she conceives border crossing as times where gender boundaries and barriers are deactivated and the gender divide can be successfully crossed. These concepts offer some possibilities as frameworks for considering social work practice with single fathers, their experiences and how they interact with complex maternal-dominated worlds. They will be interweaved through this paper to cultivate understanding of the experiences of single fathers with social work.

Single fathers cross gender borders and enter female-dominated spaces when accessing health visiting services, children's centres or social work support and entering the school playground or discussions about employment and caring responsibilities for example. This can involve moving between equality and difference, and between stereotypically masculine and female roles and tasks. As will be seen below, single fathers can find social work to be excluding and stigmatising, while the narratives of social workers can be based upon common gender stereotypes. The concept of borderwork will be used to articulate some of the links between stereotyping, marginalisation and heteronormative assumptions about parenting evident within social work practice with single fathers.

\section{Methodology}

A systematic literature review was undertaken employing established methods of formulating questions, inclusion and exclusion criteria and a search strategy, followed by quality appraisal and data analysis (Bryman, 2014; Gough, 2007). This review uses a method of systematic literature reviews that include qualitative as well as quantitative research. As Dixon-Woods and Fitzpatrick (2001) identified a number of years ago 'The argument for giving a place to qualitative research in systematic reviews seems to have been won' (p.765).

Systematic literature reviews can bring together all known knowledge on a topic area, identify important gaps in the evidence base, provide new analyses and insights yet to be discovered within the available research literature and disseminate findings in an explicit and systematic manner (Rutter et al, 2010; Grant \& Booth, 2009). This review has aimed to realise these prospective strengths and provide as broad and detailed understanding of social work with single fathers as is possible from the research literature.

Clear inclusion and exclusion criteria were set to focus the review and identify literature that addresses the research questions (Bryman, 2014). No limits were placed on the year 
or country of the study, but only completed studies were included. The search was limited to literature published in the English language and included only published literature. Search terms were developed and refined after an initial trial search. The final search strings were:

Father* OR Dad* AND Lone OR Single AND Social Work* AND Stud* OR Research

Relevant specialised electronic databases were identified based upon their relevance to the topic and social work. The following nine databases were searched: ASSIA, Social Services Abstracts, IBSS, Social Sciences Citation Index, Campbell Collaboration Library, Cochrane Library, Social Care Online, ZETOC and Ethos. 'Snowballing' and hand searching were employed to potentially identify further studies.

The searches generated a total of 5,236 references. 2, 989 references were excluded after reading the title and a further 2, 174 after reading the abstract, based on applying the inclusion and exclusion criteria. 73 full articles were read as they were considered to be of potential relevance and seven papers were consequently finally included. Articles were omitted at this stage due to a lack of focus upon single fathers and/or social work. The included papers were:

\begin{tabular}{|c|c|c|c|c|}
\hline Author(s) & Date & Title & Research Method(s) & Main Findings \\
\hline $\begin{array}{l}\text { Cohen, } \\
\text { O., Finzi- } \\
\text { Dottan, } \\
\text { R. \& } \\
\text { Tangir- } \\
\text { Dotan, G. }\end{array}$ & 2014 & $\begin{array}{ll}\text { The } & \text { Fatherhood } \\
\text { Experience of Divorced } \\
\text { Custodial Fathers in } \\
\text { Israel }\end{array}$ & $\begin{array}{l}\text { Qualitative: Semi- } \\
\text { structured interviews. } \\
\text { Research sample } 20 \\
\text { divorced single fathers } \\
\text { in Israel (non- } \\
\text { random). }\end{array}$ & $\begin{array}{l}\text { Conceptualised } \\
\text { single fatherhood as } \\
\text { a choice but also } \\
\text { constraint and } \\
\text { relationships with } \\
\text { children's mothers } \\
\text { were found to hold } \\
\text { significance. }\end{array}$ \\
\hline Coles, R. & 2003 & $\begin{array}{l}\text { Black Single Custodial } \\
\text { Fathers: } \\
\text { Influencing the Dectors } \\
\text { to Parent }\end{array}$ & $\begin{array}{l}\text { Quantitative } \\
\text { questionnaires and } \\
\text { qualitative interviews. } \\
\text { Research sample } 10 \\
\text { African American } \\
\text { Fathers (non-random). }\end{array}$ & $\begin{array}{l}\text { Found a distinction } \\
\text { between } \text { enabling } \\
\text { and } \quad \text { motivating } \\
\text { factors into primary } \\
\text { caregiving. }\end{array}$ \\
\hline $\begin{array}{l}\text { Kullberg, } \\
\text { C. }\end{array}$ & 2004 & $\begin{array}{l}\text { Work and } \begin{array}{r}\text { Social } \\
\text { Support: }\end{array} \text { Social } \\
\text { Workers' } \text { Assessments } \\
\text { of Male and Female } \\
\text { Clients' Problems and } \\
\text { Needs }\end{array}$ & $\begin{array}{l}\text { Quantitative: Gender- } \\
\text { comparative vignette } \\
\text { based questionnaire. } \\
\text { Research sample } 880 \\
\text { Swedish social workers } \\
\text { (random). }\end{array}$ & $\begin{array}{l}\text { Found that } \\
\text { practitioners largely } \\
\text { conformed to } \\
\text { heteronormative } \\
\text { expectations of } \\
\text { mothers and fathers, } \\
\text { linking single } \\
\text { fathers' issues more } \\
\text { with paid work but } \\
\text { single mothers more } \\
\text { with social networks. }\end{array}$ \\
\hline
\end{tabular}




\begin{tabular}{|c|c|c|c|c|}
\hline $\begin{array}{l}\text { Kullberg, } \\
\text { C. }\end{array}$ & 2005 & $\begin{array}{l}\text { Differences in the } \\
\text { Seriousness of Problems } \\
\text { and Deservingness of } \\
\text { Help: Swedish Social } \\
\text { Workers' Assessments } \\
\text { of Single Mothers and } \\
\text { Fathers }\end{array}$ & $\begin{array}{l}\text { Quantitative: Gender- } \\
\text { comparative vignette } \\
\text { based questionnaire. } \\
\text { Research sample } 880 \\
\text { Swedish social workers } \\
\text { (random). }\end{array}$ & $\begin{array}{lr}\text { Found } & \text { that } \\
\text { practitioners } & \\
\text { assessed } & \text { single } \\
\text { fathers as } & \text { having } \\
\text { more } & \text { serious } \\
\text { problems. Its results } \\
\text { suggested } & \text { that } \\
\text { support } & \text { offered } \\
\text { followed } & \text { gender- } \\
\text { traditional patterns. }\end{array}$ \\
\hline $\begin{array}{l}\text { McArthur, } \\
\text { M. et al. }\end{array}$ & 2006 & $\begin{array}{l}\text { Dad, Where are we } \\
\text { Going to Live Now? } \\
\text { Exploring Fathers' } \\
\text { Experiences of } \\
\text { Homelessness }\end{array}$ & $\begin{array}{l}\text { Qualitative interviews. } \\
\text { Research sample five } \\
\text { fathers in one } \\
\text { Australian territory } \\
\text { who had experienced } \\
\text { homelessness (non- } \\
\text { random). }\end{array}$ & $\begin{array}{l}\text { Identified that the } \\
\text { single fathers had a } \\
\text { strong desire to be } \\
\text { 'good' fathers, but } \\
\text { had a certain } \\
\text { reluctance to seek } \\
\text { professional support. }\end{array}$ \\
\hline $\begin{array}{l}\text { Miall, C. } \\
\& \text { March, } \\
\mathrm{K}\end{array}$ & 2005 & $\begin{array}{l}\text { Community Attitudes } \\
\text { toward Birth Fathers' } \\
\text { Motives for Adoption } \\
\text { Placement and Single } \\
\text { Parenting }\end{array}$ & $\begin{array}{l}\text { Qualitative interviews } \\
\text { with sample of } 82 \\
\text { 'community members' } \\
\text { and quantitative } \\
\text { questionnaires with a } \\
\text { random sample of } 706 \\
\text { respondents that was } \\
\text { Canada-wide. }\end{array}$ & $\begin{array}{l}\text { Found that } \\
\text { community attitudes } \\
\text { were more positive } \\
\text { towards birth fathers } \\
\text { raising their children } \\
\text { over adoption. }\end{array}$ \\
\hline Saleh, M. & 2013 & $\begin{array}{l}\text { Child Welfare } \\
\text { Professionals' } \\
\text { Experiences in Engaging } \\
\text { Fathers in Services }\end{array}$ & 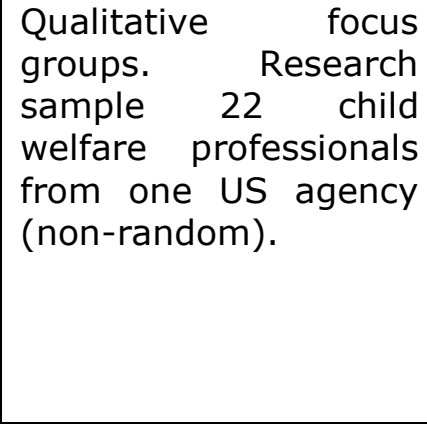 & $\begin{array}{l}\text { Significant } \\
\text { proportion of the } \\
\text { findings not } \\
\text { specifically focussed } \\
\text { on single fathers. } \\
\text { Suggested that child } \\
\text { welfare professionals } \\
\text { could engage } \\
\text { fathers, especially if } \\
\text { specifically trained. }\end{array}$ \\
\hline
\end{tabular}

Table 1: Search outputs

Quality appraisal was used to ascertain the credibility, relevance and trustworthiness of the included studies, based upon the weight of evidence approach. Each study was critically appraised and categorised as low, medium or high in terms of trustworthiness (generic criteria), appropriateness (review-specific research design criteria) and relevance (review-specific evidence focus criteria) (Carpenter, Webb \& Bostock, 2013).

This review used the hierarchy of evidence proposed by Daly et al (2007) to assess the research in terms of trustworthiness. This hierarchy grades studies from the lowest level IV for single case study, descriptive study at level III, conceptual study at level II and at the apex, generalisable studies at level I. Relevance was a significant consideration as a number of the studies included were undertaken to answer quite different questions from those of this review. Therefore, questions of focus and purpose, study design, outcomes measured and analysis of results were attended to by referring to this review's research 
questions and analysing these criteria accordingly (Rutter et al, 2010). Informed judgements about the relevance of each study were then made.

This review gave equal weighting to each criteria and calculated an average of the three criteria to produce an overall judgement on the strength of evidence each study provides. It is noteworthy that none of the papers selected were rated as high based on any of the criteria. Table 2 provides a weight of evidence summary:

\begin{tabular}{|l|c|c|c|c|}
\hline \multicolumn{1}{|c|}{ Author(s) } & Trustworthiness & Appropriateness & Relevance & Overall \\
\hline $\begin{array}{l}\text { Cohen, O., } \\
\text { Finzi-Dottan, } \\
\begin{array}{l}\text { R. \& Tangir- } \\
\text { Dotan, G. }\end{array}\end{array}$ & Low & Medium & Low-Medium \\
\hline Coles, R. & Low & Low-Medium & Low & Low \\
\hline $\begin{array}{l}\text { Kullberg, C. } \\
(2004)\end{array}$ & Medium & Low & Medium-Low & Medium-Low \\
\hline $\begin{array}{l}\text { Kullberg, C. } \\
(2005)\end{array}$ & Medium & Low & Medium-Low & Medium-Low \\
\hline $\begin{array}{l}\text { McArthur, M. } \\
\text { et al. }\end{array}$ & Low & Low-Medium & Low & Low \\
\hline $\begin{array}{l}\text { Miall, C. \& } \\
\text { March, K }\end{array}$ & Medium & Low-Medium & Low & Low-Medium \\
\hline Saleh, M. & Low-Medium & Medium & Low-Medium & Medium-Low \\
\hline
\end{tabular}

Table 2: Weight of evidence summary

Thematic analysis was the chosen method for data analysis; as Braun and Clarke (2009) suggest it can be a valuable method for identifying themes within data, describing the data in great detail and developing fresh interpretations and meaning. The analysis focussed upon a rich depiction of the entire data set, as this is an under-researched area with a scarcity of available research (Braun \& Clarke, 2009). As Fingeld (2003) suggests the aim of a literature review is to 'produce a new and integrative interpretation of findings that is more substantive than those resulting from individual investigation' (p.894).

However, like any research, this review has some limitations that mean that the findings should be interpreted appropriately. The reliance upon electronic databases for searching, combined with inclusion criteria including English-only studies, has raised the potential for a bias towards more recent studies from the USA or UK. The studies employed mostly descriptive methods and were mainly based on small and specifically selected participant samples. Thus, their findings are not generalisable. Furthermore, none of the included studies were UK based, meaning that transferring the findings to the UK would need to be undertaken with care. 


\section{The Findings}

Themes were derived from the data identified as important and relevant to this review (Braun \& Clarke, 2009). The review found negligible research into social work with single fathers and this should be considered a finding in itself. Of the seven studies, only three were focussed on social work or child welfare services and none of the studies were UK based, instead from countries with different cultural, legal and political contexts influencing social work (Green, 2009). This incorporated Sweden, Australia, Canada, USA and Israel.

This review has been conducted in the UK and considers the findings in relation to UK social work policy, practice and research. Two predominant themes were generated from the analysis: misunderstanding and stereotyping of single fathers by social workers; and lack of social workers' engagement and support of single fathers.

\section{Theme 1: Misunderstanding and stereotyping}

Analysis suggested social workers did not genuinely or comprehensively understand the needs of single fathers, rather tending to stereotype along heteronormative and gendered lines. This theme aligns with community and societal attitudes and gendered assumptions about caring, as well as an inability to recognise single fathers as a unique group with unique experiences. This theme was represented in all of the seven selected studies: Cohen, Finzi-Dottan and Tangir-Dotan (2014), Coles (2003), Kullberg (2004), Kullberg (2005), Mcarthur et al (2006), Miall and March (2005) and Saleh (2013).

In Coles' study on black single fathers in the USA, subjective data from fathers revealed that they felt services were not designed or organised to support single fathers, rather that they were principally intended for women. For example, one father stated that '...I felt the system doesn't work for fathers as much as for mothers. I can't blame the system, because most of the single parents are mothers. But I definitely feel that it doesn't work for fathers...' (p.256).

Kullberg's studies from Sweden analysed responses from a random sample of 880 Swedish social workers to a gender-comparative vignette presenting a single father and single mother facing very similar problems. They found that social workers assessed the single father as having more serious problems and yet less deserving of support. Practitioners were also less likely to assess that the single father had taken sufficient steps to address the presenting issues and more likely to assess him as more responsible for his own situation. Kullberg's (2005) paper states that 'the results lend some support to the hypothesis that single fathers in the situation in question tend to be assessed as being 
less deserving of help from the social services than single mothers in the same situation' (p.379). Furthermore, in Kullberg's research, the single mother's social networks were viewed by social workers through a more holistic lens, with parents, social workers and the social work agency all viewed as more important sources of support than for the single father. For single fathers, a permanent relationship with a partner was viewed as the priority.

Saleh's research with 22 child welfare practitioners in one state in the USA focussed upon their experiences of, and perspectives towards, working with fathers. This revealed that foster carers could hold negative stereotypical views towards single fathers; in one case the foster carer actually tried to restrict the father's contact with his children. Meanwhile, in their study into fathers' pathways into homelessness in an Australian territory McArthur et al found that single fathers held beliefs that services, including social work, were not designed to include them and were inadequate for their needs, 'with the strong suggestion that men were not regarded as potential victims of family and domestic violence' (p.296). Their study does not detail how services were experienced as inadequate. Cohen, FinziDottan and Tangir-Dotan's research within Israel identified that single fathers were not conceived as a unique group by professionals. Their research suggested single fatherhood was experienced as a complex mix of reward and responsibility.

The findings that comprise this theme start to portray that the attitudes and narratives of social workers towards single fathers in these studies were at least in part based on common gender stereotypes and that they intentionally or unintentionally served to alienate single fathers from suitable social work support and erect barriers to accessing support. The social workers, according to Kullberg (2005), 'assessed the two sexes according to different standards' (p.381), and the findings have conveyed that social workers struggled to understand single fathers' strengths and needs.

\section{Theme 2: Lack of engagement and support}

Theme two suggests that social workers did not successfully engage with single fathers or offer appropriate support. This was evident in the studies of Coles (2003), Kullberg (2004), Kullberg (2005) and McArthur et al (2006).

In Kullberg's research studies, the support offered to single fathers and mothers tended to follow traditional gender lines. Social workers assessed the single father as primarily needing support to return to work whereas they viewed the single mother's social networks as a more significant issue and assessed that she would benefit more from advice and guidance around social support networks. For example, $84 \%$ of respondents assessed that 
the single mother had serious or very serious problems in terms of her social network vs $69 \%$ for the single father.

Notably, despite both facing almost identical issues, social workers recommended less supportive measures for the single father and assessed the single mother as in greater need of support. Kullberg (2005) asserts that his findings suggest that single fathers were viewed as less deserving of help from the welfare state than single mothers. In McArthur et al's study anecdotal reports from single fathers demonstrated a distrust of services and reluctance to seek support from agencies.

As with the first theme, this theme resonates with the welfare state as conceptualised and operated along gendered stereotypes, but also binary lines, with fathers viewed as 'deserving' or 'undeserving', 'good' or 'bad' (Bowl, 2001). It raises questions about social work's role as an apparatus of states that continue to be predicated on such archaic gendered norms. It also chimes with the wider literature on social work with fathers. For instance, that social work remains dominated by psychological theories that posit women as primary carers and focusses on mothers, much less so fathers, in this role. In the process, leading to exclusion and alienation of fathers and responsibility for children being placed primarily on mothers (Scourfield, 2006; Ashley et al, 2006; Brandon, Philip \& Clifton, 2017).

\section{However, a few examples of more inclusive practice were apparent}

Saleh's study (2013) shows three examples of potentially more inclusive practice with single fathers. These included child welfare professionals discussing single fathers taking responsibility for the care of their children and challenging negative stereotypical views held by foster carers towards single fathers. One foster carer had set very high expectations that made life difficult for a single father and another had tried to restrict a father's access to his children. These examples of practice demonstrated acknowledgement and acceptance of single fathers' distinctive needs and present as a counter theme to those of misunderstanding and stereotyping and lack of engagement and support.

\section{Discussion}

The findings indicate that single fathers remain largely invisible in social work research. Only a small number of papers were considered to be relevant from the literature base and the findings of these papers suggest marginalisation and invisibility of single fathers in practice. Social work is practised at the interface between the public and the private 
and thus contributes to gender identity discourses (Christie, 2006). This review should be located within the discourse, as discussed by Christie (2001) and Featherstone (2009) amongst others, that societal assumptions about the feminised role of caring and lone parenthood can still dominate social work, excluding single fathers in the process. These narratives can stigmatise single fathers in the context of their 'non-masculine' relationships with their children and as part of a welfare state still predicated on traditional family norms.

\section{The literature reviewed overlooks the wider social context}

This review found that the research into social work with single fathers has not effectively considered the array of social influences on single fathers' capacities to parent, failing to explore the links between structural factors, social injustice and social work practice in any meaningful sense. The reviewed literature offered no cogent analysis of how single fathers' personal experiences emerge from public discourses.

Goetz (1997) identifies three main institutional arenas of state, market and community within society and suggests that organisations and social institutions such as the family are formed within these. She argues that these arenas and the institutions within them should be understood as 'frameworks for socially constructed norms which function to limit choice' (p.6), but frameworks that are open to change. Social work can be conceived as straddling the state and community arenas and it is important to analyse how hospitable these arenas and social work are to single fathers; and how intensely gender differences are perceived and experienced. It is apparent that practice is influenced by normative gendered ideologies that stigmatise, but it remains unclear whether this leads to unequal outcomes for single father families.

Gendered stereotypes and assumptions likely influenced social workers' assessments and narratives in the studies, leading to barriers to support being erected. As Scourfiled (2001) suggests gendered identities are constructed in practice and within practice encounters. Single fatherhood raises challenges for socially constructed gendered norms, hegemonic masculinity and how children and families social work is practised. The themes identified in the literature portray that single fathers experience challenging systems and practices when engaging with social work and can experience social work as alienating and unattentive to their holistic needs. 


\section{Returning to the concept of Borderwork}

Social work is a female-majority profession (Cree, 2001; Christie, 2001; Payne, 2006; Schaub, 2017). This review found that single fathers can be positioned as lone males within predominantly female professional networks, feeling misjudged and marginalised within these contexts. The words of Brandon, Philip and Clifton (2017) seem relevant here, when they state that: '...the longstanding issue of 'father engagement' is better understood as an interactive two-directional process, rather than a 'problem' with either men or social workers' (p.3). Clearly the gendered identities of social workers also influence such engagement (Pringle, 2001; Scourfield, 2001).

Doucet (2006) describes that borderwork can engender conflict and intense feelings, while involving gender boundaries that can be strong and rigid. Through daily interactions and interactions with social work single fathers are engaging in borderwork and border crossing, when the stakes are often high. They act as primary carers for their children within a female-dominated terrain, under a social gaze dominated by social and community norms on caring and masculinity from which they stray (Doucet, 2006). They may try to conform to socially acceptable identities and present as especially sensitive to rejection when interacting with our profession. Such rejection will clearly be exacerbated by any fixed or immovable gender borders being erected during assessments or interventions. Borderwork involves role confusion, identity management, othering and potential rejection and this will likely feed into assessments of parenting capacity. These issues can be found in both themes 1 and 2, with single fathers experiencing feelings of othering and rejection by services and the undertaking of gendered assessments by social workers.

\section{Placing these ideas within wider social work debates}

Practice with single fathers should be understood within wider debates about the current nature of children and families social work in the UK and indeed abroad, where practice is typically framed within an increasingly unequal society and increasingly bureaucratic and authoritarian systems (Featherstone, Morris \& White, 2014; Warner, 2015). Children and families social work has established barriers to the involvement of fathers (Brown et al 2009; Featherstone, 2009; Scourfield, 2006), despite the exclusion of fathers potentially increasing the risks of abuse (Douglas, 2017; Klevens \& Leeb, 2010) and research indicating that the involvement of fathers can be considered beneficial for children and their development in a variety of ways (Jones, 2008; Hauari \& Hollingworth, 2009; Field, 2010). These barriers can make successful border crossing more difficult for single fathers, as illustrated within the literature reviewed and especially theme 2 where support offered to single fathers followed traditional gendered lines for example. 
Single fathers who have previously not achieved social status through traditional masculine routes may face compounded stigma and harsh moral judgements of failure as men and fathers when social work intervenes. Ferguson and Hogan (2004) define fathers who are involved with child protection as 'vulnerable fathers' (p.3), with such vulnerability encompassing issues from relationship problems to poverty and social exclusion. This vulnerability may then be amplified or diminished by further intersectionality of advantage/disadvantage through race or sexuality for example. Each single father and their family will therefore likely have different experiences of society, culture and professional interventions.

Single fathers subject to social work interventions, experiencing compounded stigma and moral judgements, may find it even more difficult to successfully engage in borderwork and border crossing. They may consequently portray protest masculinities where they present as a threat or risk or disengage (Scourfield, 2001) and further alienate themselves from support. In effect, they are out of step with societal, community and social work norms and therefore potentially viewed with suspicion and self-suspicion. Within the literature, there was evidence of this in Cole's, Kullberg's and McArthur et al's studies.

\section{Which leads to some questions about practice}

The complex interactions between masculinity, status, intersectionality, vulnerability and marginalising or authoritarian systems need to be understood to develop inclusive practice. Therefore, mutually influencing micro-level identities and interactions need to be linked with macro-level conditions and inequalities to analyse and understand the experiences of single fathers within social work and how their masculinities are being constructed in practice. Based on the literature reviewed, there must be concern that their choices and chances are limited through borders and barriers being constructed within the institutional arenas of state and community that shape their needs and how social work responds. A pertinent question is whether children and families social work is looking to address such stigma and disadvantage, failing to challenge and address them, or in fact amplifying them. The literature reviewed mainly suggests the last of these options.

A further question is whether we are assessing and supporting single fathers through maternal lenses and female-centred practices (Doucet, 2007), reinforcing the othering and potential rejection that constitute aspects of borderwork. Doucet (2006) suggests that fathers acting as primary carers tend to show different types of nurture, for example through more playfulness. Further, that they engage in more physical activities with their 
children, with more inherent risks. In our currently risk averse professional context do assessments fairly capture these styles of care? Certainly, from the literature reviewed, social workers' assessments and views tended to reflect gendered and heteronormative assumptions about men and caring. If assessments do not, the question needs to be asked as to how single fathers' narratives can be heard and social work can develop more inclusive and less judgemental practice.

\section{More inclusive practice?}

The pockets of potentially more inclusive and non-judgemental practice with single fathers recognised in Saleh's study are therefore clearly worthy of discussion. These included one single father actively engaging with social work support and social workers respectfully challenging prospective single fathers about their own gendered views of caregiving.

Writers such as Featherstone (2009) and Ashley (2006) have proposed that fatherinclusive practice is influenced by institutional norms and practitioners' constructions of gender and parenting. This was indicated within theme 2, where such norms and constructions fostered single father-exclusive practice. Father-inclusive practice for single or other fathers can be understood to feature practical support, a sense of collaboration and the promotion of more expressive and self-aware masculinities (Ashley et al, 2006; Ferguson \& Hogan, 2004). It is only then that the conditions for successful border crossing can be supported, where single fathers can, as Doucet (2006) articulates, 'challenge the oppositional structure of traditional gender arrangements around parenting' (p.201). Successful border crossing requires social acceptance, moral verification and challenging stereotypical suspicions of men as primary caregivers (Doucet, 2006).

Within the literature reviewed, Coles suggests that practitioners should directly target single fathers to inform them about available support services. She also recommends that non-resident fathers should be approached as potential carers for their children, adding that few parents fall simply into a good or bad category. Meanwhile, Cohen, Finzi-Dottan and Tangir-Dotan recommend that single fathers need to be recognised as a unique group with unique paternal identities, and that through such recognition professionals can focus more effectively on their needs. These suggestions should arguably form part of a systemic change in social work practice where support to single fathers can start to act as a bridge to more comfortable and stress-free engagement with female-dominated professional networks of support, parenting communities and community/societal networks.

The engagement of single fathers should form part of everyday practice, but this requires structural, cultural and individual changes, including challenging widespread gender 
stereotypes and assumptions (Brandon, Philip \& Clifton, 2017). Inclusive and gendersensitive social work with single fathers would appreciate the roles of borderwork and stigma in life chances and engagement with services, while being alert to gender theorising (Scourfield, 2001); recognising patriarchal privilege while engaging with the gender complexities and contradictions posed by single fatherhood.

\section{Conclusion and Recommendations}

This literature review has identified a neglected research area and shown that there is a clear absence of systematic knowledge about social work practice with single fathers to draw any clear conclusions about their experiences with children and families social work, the nature and quality of practice or whether practice is inclusive and supportive. Thus, further primary empirical research is recommended.

The literature portrayed that practice tends to exclude and marginalise single fathers and that social workers generally did not effectively understand their needs or successfully engage with them. Within this paper, these themes have been related to the concept of borderwork. As there has been negligible empirical research into this area, practitioners have little research evidence to inform their practice, leading to few examples of lessons being applied in practice. It appears a negative cycle has therefore been established, where research is not informing practice and practice is not informing research.

Thus, it can be argued that further in-depth qualitative research should be undertaken to explore single fathers' experiences of social work and how gendered stereotypes and stigma may influence policy and practice. Such research could also explore how practitioners can be supported to effectively work with single fathers and whether social work recognises potential distinctive parenting styles of single fathers in assessments and interventions. Perhaps most importantly, as Smith (2009) proposes, any future research should ask questions of what changes can be anticipated if it is undertaken and how can these changes be taken forward. 


\section{$\underline{\text { References }}$}

Ashley, C. et al (2006) Fathers matter. London, Family Rights Group.

Bowl, R. (2001) 'Men and Community Care' in Christie, A. (ed.) Men and Social Work Theories and Practices. Basingstoke, Palgrave: pp. 109-125.

Brandon, M., Philip, G. \& Clifton, J. (2017) Counting Fathers In: Understanding Men's Experiences of the Child Protection System. London, Nuffield Foundation.

Braun, V. \& Clarke, V. (2006) 'Using thematic analysis in psychology'. Qualitative Research in Psychology. 3(2): pp. 77-101.

Brewsaugh, K., Masyn, K. \& Salloum, A. (2018) 'Child welfare workers' sexism and beliefs about father involvement'. Children and Youth Services Review. 89: pp. 132-144.

Brown, L. et al (2009) 'Manufacturing ghost fathers: The paradox of father presence and absence in child welfare'. Child \& Family Social Work. 14(1): pp. 25-34.

Bryman, A. (2014) Social Research Methods $4^{\text {th }}$ ed. Oxford, Oxford University Press.

Carpenter, J., Webb, C. \& Bostock, L. (2013) 'The surprisingly weak evidence base for supervision: Findings from a systematic review of research in child welfare practice (2000-2012)'. Child and Youth Services Review. 35: pp. 1843-1853.

Christie, A. (2001) 'Gendered Discourses of Welfare, Men and Social Work' in Christie, A. (ed.) Men and Social Work Theories and Practices. Basingstoke, Palgrave: pp. 7-34.

Christie, A. (2006) 'Negotiating the uncomfortable intersections between gender and professional identities in social work'. Critical Social Policy. 26(2): pp. 390-411.

Cohen, O., Finzi-Dottan, R. \& Tangir-Dotan, G. (2014) 'The Fatherhood Experience of Divorced Custodial Fathers in Israel'. Family Relations. 63: pp. 639-653.

Coles, R. (2003) 'Black Single Custodial Fathers: Factors Influencing the Decision to Parent'. The Journal of Contemporary Human Services. 84(2): pp. 247-258.

Connell, R. \& Messerschmidt, J. (2005) 'Hegemonic Masculinity Rethinking the Concept'. Gender \& Society. 19(6): pp. $829-859$. 
Cree, V. (2001) 'Men and Masculinities in Social Work Education' in Christie, A. (ed.) Men and Social Work Theories and Practices. Basingstoke, Palgrave: pp. 147-163.

Daly, J. et al (2007) 'A hierarchy of evidence for assessing qualitative health research'. Journal of Clinical Epidemiology. 60: pp. 43-49.

Daly, M. \& Rake, K. (2003) Gender and the Welfare State: Care, Work and Welfare in Europe and the USA. Cambridge, Polity Press.

Dixon-Woods, M. \& Fitzpatrick (2001) 'Qualitative research in systematic reviews has established a place for itself'. British Medical Journal. Vol. 323(7316): pp. 765-766.

Dominelli, L. (1997) Anti-Racist Social Work. Basingstoke, Macmillan.

Doucet, A. (2000) 'There's a huge gulf between me as a male carer and women: Gender, domestic responsibility, and the community as an institutional arena'. Community, Work and Family. 3(2): pp. 163-184.

Doucet, A. (2006) 'Estrogen-filled worlds: fathers as primary caregivers and embodiment'. The Sociological Review. 54(4): pp. 696-716.

Doucet, A. (2007) Do Men Mother? Fathering, Care and Domestic Responsibility. Toronto, University of Toronto Press.

Douglas, E. (2017) Child maltreatment fatalities in the United States: Four decades of policy, program and professional responses. Dordrecht, Springer Netherlands.

Duncan, S. \& Edwards, R. (1997) 'Introduction: A contextual approach to single mothers and paid Work' in Duncan, S. \& R. Edwards, R. (eds) Single mothers in an international context: Mothers or workers? London, University College: pp. 1-15.

Featherstone, B. (2009) Contemporary Fathering Theory, Policy and Practice. Bristol, The Policy Press.

Featherstone, B. \& Lee, J. (2012) 'The Benefits and Challenges of Training Child Protection Workers in Father Engagement'. Child Abuse Review. 21: pp. 299-310.

Featherstone, B., Morris, K. \& White, S. (2014) 'A marriage made in hell: early intervention meets child protection'. British Journal of Social Work. 44: pp. 1735-1749. 
Featherstone, B. et al. (2017) 'They are just good people...generally good people: perspectives of young men on relationships with social care workers in the UK'. Children \& Society. 31: pp. 331-341.

Ferguson, H. \& Hogan, F. (2004) Strengthening Families through Fathers: Developing policy and practice in relation to vulnerable fathers and their families. Waterford, The Centre for Social and Family Research.

Field, F. (2010) The Foundation Years: preventing poor children becoming poor adults. HM Government, London.

Fingeld, D. (2003) 'Metasynthesis: the state of the art so far'. Qualitative Health Research. 13(7): pp. 893-904.

Garner, S. (2009) 'Home Truths: The White Working Class and the Racialization of Social Housing' in Sveinsson, K. (ed) Who Cares about the White Working Class. London, Runnymede Trust: pp. 45-50.

Gough, R. (2007) 'Weight of evidence: a framework for the appraisal of quality and relevance of evidence'. Research Papers in Education. 22: pp. 213-218.

Grant, M. \& Booth, A. (2009) 'A typology of reviews: an analysis of 14 review types and associated methodologies'. Health Information and Libraries Journal. 26: pp. 91-108.

Green, B. (2009) Understanding and Researching Professional Practice. Rotterdam, Sense Publishers.

Gupta, A. (2015) 'What about my dad? Black fathers and the child protection system'. Critical and Radical Social Work. 4(1): pp. 77-91.

Hauari, H. \& Hollingworth, K. (2009) Understanding Fathering Masculinity, Diversity and Change. Joseph Rowntree Foundation, York.

Jones, K (2008) 'Assessing the Impact of Father-Absence from a Psychoanalytic Perspective'. Psychoanalytic Social Work. 14(1): pp. 43-58.

Klevens, J. \& Leeb, R. (2010) 'Child maltreatment fatalities in children under 5: Findings from the National Violence Death Reporting System'. Child Abuse \& Neglect. 34(4): pp. 262-266.

Kiteley, R. and Stogdon, C. (2014) Literature Reviews in Social Work. London, Sage. 
Kullberg, C. (2004) 'Work and Social Support: Social Workers' Assessments of Male and Female Clients' Problems and Needs'. Journal of Women and Social Work. 19(2): pp. 199-210.

Kullberg, C. (2005) 'Differences in the Seriousness of Problems and Deservingness of Help: Swedish Social Workers' Assessments of Single Mothers and Fathers'. British Journal of Social Work. 35: pp. 373-386.

Letablier, M. \& Wall, K. (2018) 'Changing Lone Parenthood Patterns: New Challenges for Policy and Research' in Bernadi, L. \& Mortelmans, D. (eds) Lone Parenthood in the Life Course.

Gewerbestrasse, Springer Open: pp. 29-54.

McArthur, M. et al (2006) 'Dad, Where are we Going to Live Now? Exploring Fathers' Experiences of Homelessness'. Australian Social Work. 59(3): pp. 288-300.

Miall, C. \& March, K. (2005) 'Community Attitudes toward Birth Fathers' Motives for Adoption Placement and Single Parenting'. Family Relations. 54(4): pp. 535-546.

Office for National Statistics (ONS) (2016) Families and households in the UK: 2016. Available at: www.ons.gov.uk (Accessed $12^{\text {th }}$ February 2018).

Parker, K. \& Livingston, G. (2017) 6 facts about American fathers. Available at: www.pewresearch.org (Accessed 14 ${ }^{\text {th }}$ March 2018).

Pascall, G. (2012) Gender Equality in the Welfare State? Bristol, Policy Press.

Paterson, B. et al (2001) Metastudy of Qualitative Health Research. Thousand Oaks, Sage.

Payne, M. (2006) What is professional social work? Bristol, Policy Press.

Philip, G. (2013) 'Relationality and moral reasoning in accounts of fathering after separation or divorce: care, gender and working at 'fairness". Families, Relationships and Societies. 2(3): pp. 409424.

Pringle, K. (2001). 'Men in social work: The double-edge' in Christie, A. (ed.) Men and Social Work Theories and Practices. Basingstoke, Palgrave: pp. 35-48.

Risley-Curtiss, C. \& Heffernan, K. (2003) 'Gender biases in child welfare’. Affilia. 18(4): pp. 395-410.

Rutter, D et al (2010) SCIE systematic research reviews: guidelines $2^{\text {nd }}$ ed. London, SCIE. 
Saleh, M. (2013) 'Child Welfare Professionals' Experiences in Engaging Fathers in Services'. Child and Adolescent Social Work Journal. 30(2): pp. 119-137.

Schaub, J. (2017) Making sense of men's experiences and progression through social work programmes. Unpublished PhD Thesis, University of Bath.

Scottish Parliament (2014) Equal Opportunities Committee 1 1' Report, 2014 (Session 4) Fathers and parenting. Available at: www.parliament.scot/parliamentarybusiness/CurrentCommittees/76595.aspx (Accessed 12 ${ }^{\text {th }}$ April 2018).

Scourfield, J. (2001) 'Constructing Men in Child Protection Work'. Men and Masculinities. 4(1): pp. 7089.

Scourfield, J. (2006) 'The challenge of engaging fathers in the child protection process'. Critical Social Policy. 26(2): pp. 440-449.

Shapiro, A. \& Krysik, J. (2010) 'Finding Fathers in Social Work Research and Practice'. Journal of Social Work Values and Ethics. 7(1): pp. 1-9.

Smith, C. (1998) 'Men Don't Do This Sort of Thing A Case Study of the Social Isolation of Househusbands'. Men and Masculinities. 1(2): pp. 138-172.

Smith, R. (2009) Doing Social Work Research. Maidenhead, Open University Press.

Strega, S. et al (2008) 'Connecting father absence and mother blame in child welfare policies and practice'. Children and Youth Services Review. 30(7): pp. 705-716.

Thorne, B. (1993) Gender Play: Girls and Boys in School. Buckingham, Open University Press.

Warner, J. (2015) The Emotional Politics of Social Work and Child Protection. Bristol, Policy Press. 